\section{Commentary: Go out on a limb, that's where the fruit is!}

\author{
Aaron Eckhauser, MD, MS
}

In this issue of the Journal, Castellanos and colleagues ${ }^{1}$ present a case in which a left ventricular pseudoaneurysm developed after a Melody valve in the mitral position was explanted and re-replaced with a mechanical valve. The patient was born with a transitional atrioventricular canal defect, hypoplastic aortic arch, and multiple ventricular septal defects (VSDs). After multiple surgeries, the child developed severe left atrioventricular valve regurgitation, and the decision was made to replace the valve with a Melody valve. The authors assumed care of this patient years later, when the valve had failed. During valve re-replacement surgery, the authors described an extensive sharp dissection toward the apical end of the valve where the stent tines had been anchored to the posterior ventricular free wall. Postoperatively, a small pseudoaneurysm was identified on echocardiography that progressed over time and ultimately required repair with a patch exclusion from within the ventricle.

Broadly speaking, this case highlighted for me the dualistic nature of innovation in our specialty: the life-giving benefits of new techniques and technologies balanced against the Pandora's box of unforeseen complications and consequences of these technologies. My initial reaction was how can we attribute this outcome to the Melody valve itself rather than to an accepted risk of a complex reoperative surgery? In retrospect, I missed the point: the Melody is not a flawed technology, but it was never meant to be used in this manner. Our desire to innovate and push the boundaries of what these technologies were created for simply speaks to the fact that what we currently have is not good enough. The authors' point was not meant to be an endorsement or condemnation of the Melody valve, but rather an

\footnotetext{
From the Division of Cardiothoracic Surgery, Department of Surgery, University of Utah, Salt Lake City, Utah.

Disclosures: The author reported no conflicts of interest.

The Journal policy requires editors and reviewers to disclose conflicts of interest and to decline handling or reviewing manuscripts for which they may have a conflict of interest. The editors and reviewers of this article have no conflicts of interest.

Received for publication Oct 13, 2020; revisions received Oct 13, 2020; accepted for publication Oct 20, 2020; available ahead of print Oct 22, 2020.

Address for reprints: Aaron Eckhauser, MD, MS, 100 N Mario Capecchi Drive, Suite 2200, Salt Lake City, UT 84113 (E-mail: Aaron.eckhauser@hsc.utah.edu).

JTCVS Techniques 2020;4:253

2666-2507

Copyright (C) 2020 The Authors. Published by Elsevier Inc. on behalf of The American Association for Thoracic Surgery. This is an open access article under the CC BY-NCND license (http://creativecommons.org/licenses/by-nc-nd/4.0/).

https://doi.org/10.1016/j.xjtc.2020.10.021
}

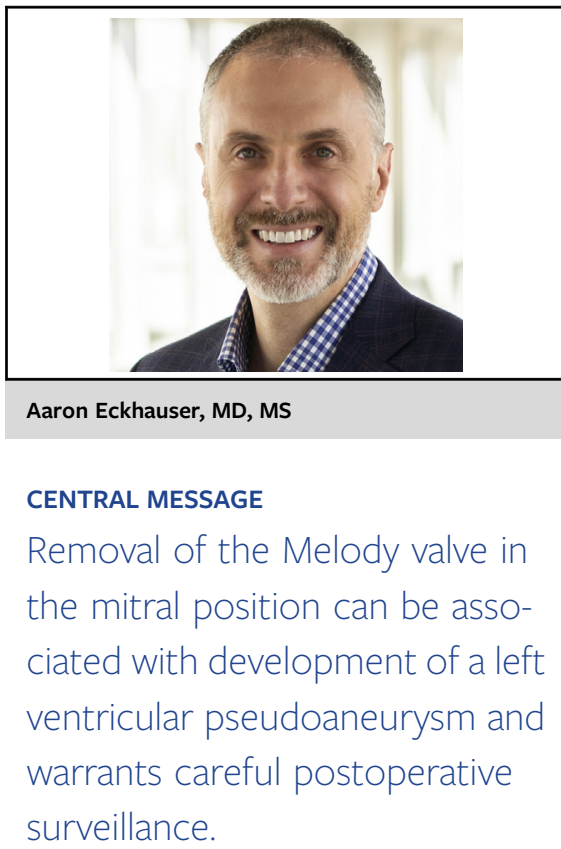

acknowledgment that we do not yet understand all the implications of these innovations.

I have recently encountered 2 similar innovative conundrums. First, we transitioned from the Melody to the Sapien valve in the mitral position because it had a nice skirt already attached to the annulus, was shorter, and did not require apical securement, and the outflow tines were unobstructed, and it seemed a better choice to protect the left ventricular outflow tract. However, the leaflets are thicker, and the valve does not function well when underdeployed, even by $1 \mathrm{~mm}$. All of our implants failed rapidly with thrombosis of the septal leaflet, an unintended and unforeseen consequence. Second, during the early stages of perventricular device closure of VSDs, we struggled to find the ideal puncture location and ensure visualization of the delivery sheath across the defect. As a result, 2 of our patients developed a posterior left ventricular free wall aneurysm from either wire or sheath injury during positioning. One of these aneurysms was addressed in the catheterization lab, and the other required reoperation to repair the aneurysm externally - again, an unexpected and unintended consequence.

I thank the authors for broadening our collective knowledge by openly sharing their case and how they dealt with their complication. Innovation is the lifeblood of our specialty, but vigilance and equipoise will ensure its survival.

\section{Reference}

1. Castellanos DA, Jaquiss RDB, Thankavel PP. Left ventricular pseudoaneurysm after replacement of a melody valve in the left atrioventricular valve position. J Thorac Cardiovasc Surg Tech. 2020;4:248-50. 